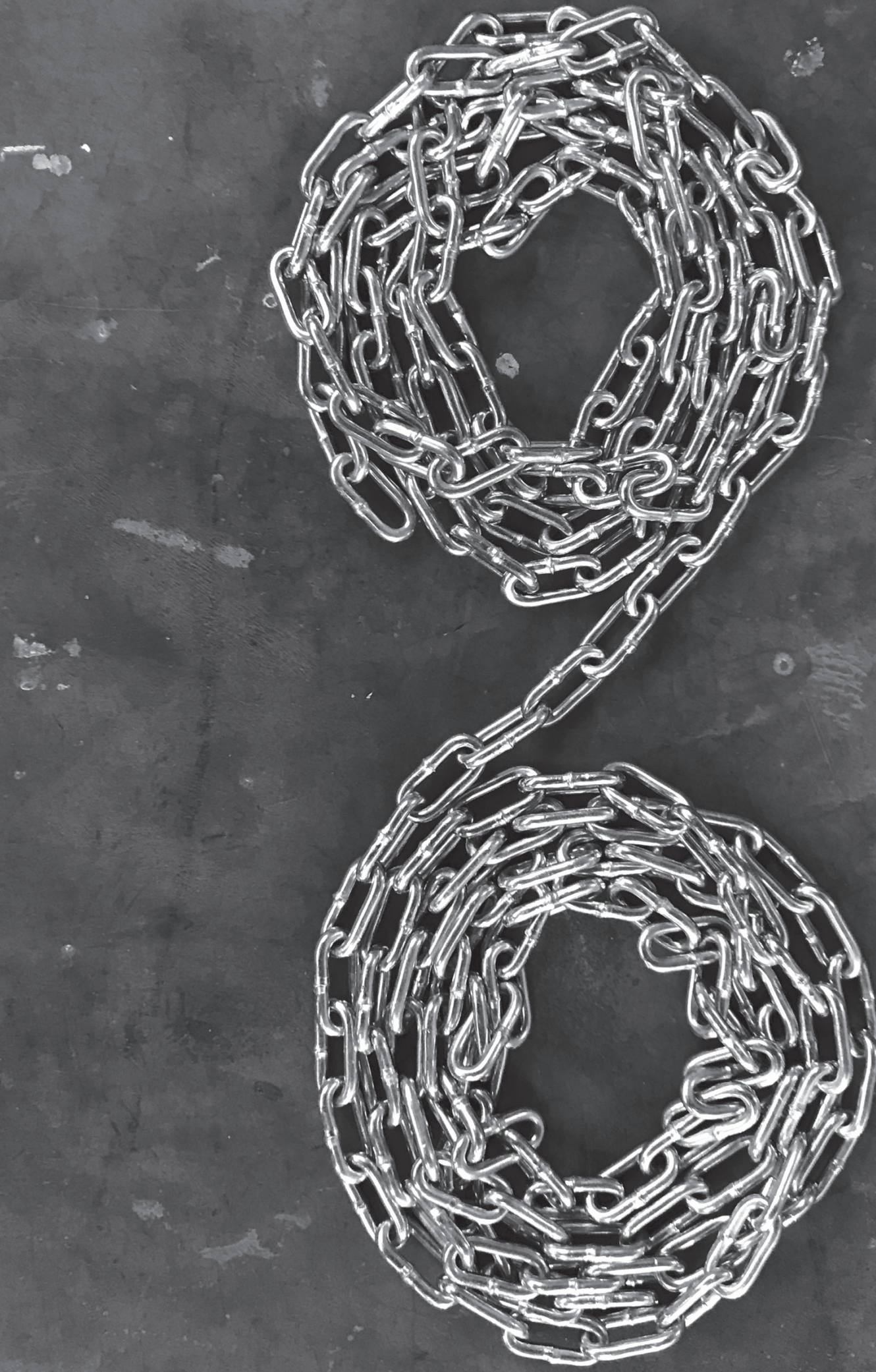




\section{APRESENTAÇÃO: OUTRA FANTASIA DESFEITA, OUTRO BALANÇO CRÍTICO}

http://dx.doi.org/10.25091/ Solo13300201800020001

[*] Universidade de São Paulo, São Paulo, SP, Brasil. E-mail: rugitsky@ usp.br
FERNANDO RUGITSKY*

Quando Celso Furtado dedicou-se a escrever seu testemunho sobre as disputas políticas e econômicas das décadas de 1950 e 1960, caracterizou o período como uma fantasia que acabou sendo desfeita. Ele sugere, assim, que o otimismo e a esperança da época, em que a superação do subdesenvolvimento da economia brasileira parecia estar ao alcance da mão, tinham algo de ilusório, fantasioso. A ruptura brusca e violenta ocorrida em 1964, com o golpe civil-militar, desfez a fantasia, jogando luz sobre as tensões que vinham se acumulando até ali. Narrando sua partida para o exílio, Furtado (2014, p. 496) ressalta a força da desilusão: "Agora, essa fantasia estava desfeita, desmoronara como uma estrela que se estilhaça. Era como se uma enxurrada tudo houvesse arrastado".

Ressalvadas as diferenças entre o período que o autor examina e o momento atual, a ideia de uma fantasia que se desfaz cai também como uma luva para descrever a brusca reversão de expectativas que se observou no Brasil sobretudo a partir de 2013 ou 2015, conforme o observador. Passou-se, em um intervalo curto de tempo, do otimismo para o desalento, do crescimento para o colapso econômico, da sensação de que os problemas estavam sendo superados para o sentimento de que não há saídas para a crise.

Embora socialmente dramáticos, tais períodos de crise servem de estímulo à reflexão. Foi assim no final dos anos 1960, quando se elaborou uma série de revisões críticas das interpretações anteriores sobre a economia, a sociedade e a política brasileiras. Várias dessas revisões foram formuladas, aliás, no próprio Centro Brasileiro de Análise e Planejamento (Cebrap) e publicadas como Estudos Cebrap.

Esse tipo de balanço crítico voltou a ser fundamental. A experiência dos últimos quinze anos, desde a chegada do Partido dos Trabalhadores (PT) à presidência até os colapsos tanto econômico quanto político atuais, precisa ser analisada em detalhe e sob diversos pontos de vista, para que suas lições sejam aprendidas. No calor do momento, 
odebate compreensivelmentevolta-se para o contrasteentre as opções políticas anteriores ao golpe parlamentar de 2016 e aquelas que prevaleceram na sua sequência, colocando o acento nas descontinuidades. Não há dúvida de que houve enormes descontinuidades e retrocessos. Mas uma revisão crítica precisa ir além de tal contraste, investigando os limites, as tensões e as consequências da trajetória anterior, que, ainda que não tenha determinado a forma específica que assumiu seu desfecho, em 2016, em certa medida assentou as bases do que ocorreu (Oliveira, 1972, pp.40-41). ${ }^{1}$

No caso específico da economia,essa perspectiva significa não restringir o debate às decisões de política econômica (ver, por exemplo, Carneiro, Baltar e Sarti, 2018). Muito embora seja crucial examinar em detalhes todas as mudanças de orientação da política econômica e seus efeitos sobre a economia, um balanço crítico também precisa explicar por que elas ocorreram, identificando em que medida elas estavam inscritas nos conflitos gestados nos anos anteriores. Evita-se, assim, analisar a política econômica de modo tecnocrático, como se o Ministério da Fazenda pairasse sobre a sociedade, completamente alheio às disputas entre seus diferentes setores. Foca-se alternativamente na economia política da política econômica, examinando os interesses promovidos por determinadas políticas, os grupos prejudicados, as correlações de forças cambiantes e a permanente disputa sobre a legitimidade das escolhas realizadas.

Os artigos que compõem o presente dossiê são uma contribuição para esse balanço crítico. Seu foco recai menos sobre os antecedentes imediatos do colapso dos últimos anos do que sobre a análise da trajetória da economia brasileira desde 2003, de modo a dar destaque às suas contradições, ao que havia de fantasioso na harmonia provisória entre crescimento e redução das desigualdades salariais. Sem negar as inquestionáveis conquistas do período, tal ênfase permite avançar na explicação da ocorrência da "contrarrevolução sem revolução", tomando emprestada a imagem sugerida por André Singer (2018, p.17), evitando considerar o golpe de 2016 um raio em céu azul. Permite aprender com o passado para que se possam vislumbrar as reais possibilidades de se trilhar o caminho da construção de uma sociedade mais justa e solidária.

O artigo "Conflito distributivo e o fim da 'breve era de ouro' da economia brasileira", escrito por Franklin Serrano e Ricardo Summa, oferece uma interpretação para a interrupção do processo de crescimento com inclusão social, em 2015, focada justamente no acirramento do conflito distributivo que se observou no período anterior. Os autores
[1] Perspectiva semelhante, ainda que referida ao balanço crítico estimulado pelo golpe de 1964 , foi defendida por Francisco de Oliveira (1972, pp. 40-41) 
resgatam o argumento de Michal Kalecki em "Aspectos políticos do pleno emprego", segundo o qual os capitalistas reagem à manutenção da taxa de desemprego em níveis baixos por períodos longos com pressões por políticas de austeridade. Seu objetivo, segundo Kalecki (1943, p. 326), seria evitar que o nível reduzido do desemprego colocasse em risco a "estabilidade política" e a "disciplina nas fábricas".

Além de oferecer sua interpretação acerca dos determinantes políticos e econômicos da crise atual, Serrano e Summa explicitam os pressupostos teóricos de sua leitura e criticam, a partir deles, interpretações alternativas. No debate econômico interno ao campo crítico, há certo consenso de que a crise está relacionada ao aprofundamento do conflito distributivo que se observa, pelo menos, desde o primeiro governo de Dilma Rousseff, com a continuidade da redução do percentual dos lucros na renda. Alguns atribuem a essa queda da lucratividade a desaceleração do investimento, em uma interpretação que pode ser relacionada com as formulações de Marx sobre a reprodução cíclica do exército industrial de reserva. Outros sugerem que a desaceleração da acumulação deveria ser interpretada como uma reação política dos capitalistas às políticas adotadas e aos lucros cadentes, uma "greve de investimento". Essa interpretação segue as formulações recentes de Wolfgang Streeck. Serrano e Summa contrapõem-se a ambas, a partir de uma compreensão da relação entre lucratividade e investimento que se deve a Garegnani. O debate entre essas três visões sobre a conexão entre o conflito distributivo e a crise é um ponto de partida profícuo para a compreensão do período.

Em países em que a participação do governo nas relações econômicas é significativa, o conflito distributivo não se dá apenas na disputa entre trabalhadores e capitalistas em torno da divisão do produto, mas aparece também como um conflito sobre as fontes da arrecadação tributária e sobre a alocação do fundo público. Nesse sentido, o artigo de Lena Lavinas e Denise Gentil sobre as políticas sociais complementa o estudo de Serrano e Summa. Em trabalhos anteriores, Lavinas (2013) já havia sugerido como o Programa Bolsa Família, independentemente de seus méritos, era parte de uma mudança do paradigma da proteção social, em que esta, em vez de desmercantilizar o acesso aos direitos sociais, tenderia a reforçar os mecanismos de mercado, abrindo caminho para o aprofundamento do processo de financeirização da economia brasileira.

No artigo incluído neste dossiê, "Brasil anos 200o: a política social sob regência da financeirização", o foco recai sobre a seguridade social, a educação superior e a medicina privada. $\mathrm{O}$ argumento é que a tão celebrada expansão do acesso às universidades (sobretudo privadas) e aos planos de saúde, para camadas até então excluídas desses serviços, representou na realidade a massificação de serviços deficientes, 
cujo resultado principal foi a valorização patrimonial dos grupos privados que os provêm. O Prouni, o Fies e as medidas de incentivo à medicina privada são interpretados, desse modo, como parte de uma mesma problemática. A política social, em vez de proteger a sociedade das turbulências do mercado, acaba por alimentar a dominância da acumulação financeira.

Sob essa luz, o argumento de que os governos do PT teriam "colocado os pobres no orçamento" precisa ser mais bem avaliado. Não parece haver controvérsia, no entanto, de que os ricos não foram incluídos na base tributária. É certo que o caráter injusto do sistema tributário brasileiro, com alta participação da tributação indireta e pouca progressividade na tributação direta, não foi introduzido no período analisado. Contudo, ele tampouco foi enfrentado, restando intocado como estrutura de reprodução da desigualdade de renda e riqueza. Esseé um dos assuntos abordados no artigo de Rodrigo Oraire Sérgio Gobetti, "Reforma tributária no Brasil: princípios norteadores e propostas em debate".

Os autores vão além da caracterização crítica usual do sistema tributário brasileiro, analisando em detalhes a tributação sobre bens e serviços, sobre folha de pagamentos e sobre a renda e explicitando suas características negativas (para além da regressividade, o viés anticrescimento, o estímulo aos conflitos federativos e a volatilidade da arrecadação). Além disso, sua descrição das tendências tributárias internacionais sugere que o caso brasileiro, já peculiar em sua baixa progressividade, parece estar em vias de se tornar ainda mais isolado, uma vez que a tributação sobre a pessoa jurídica e sobre a folha de pagamento, com alíquotas em queda, vem sendo substituída pela elevação da tributação sobre a renda e o patrimônio dos mais ricos. A peculiaridade nacional explica, ao menos em parte, a razão pela qual o percentual da renda nacional apropriada pelos mais ricos permaneceu constante (em um patamar tão elevado) ao longo dos últimos anos. Essa estabilidade, revelada recentemente pelas pesquisas com dados tributários, impediu que a desigualdade de renda diminuísse significativamente, apesar de ter ocorrido uma efetiva compressão das disparidades salariais.

Um balanço crítico da economia brasileira não estaria completo, no entanto, sem uma discussão sobre a estrutura produtiva, cuja fragilidade tantas vezes foi responsável pela interrupção de expansões econômicas, em geral na forma de crises cambiais. $\mathrm{O}$ assunto é examinado no artigo, "Complexidade econômica e desenvolvimento: uma análise do caso latino-americano", de Júlia Alencar, Elton Freitas, João Romero e Gustavo Britto. Nele, a metodologia desenvolvida por Ricardo Hausmann e César Hidalgo para medir a complexidade econômica dos países é relacionada com a tradição estruturalista e utilizada para avaliar a economia brasileira desde 1960, em comparação com as economias argentina, chilena e mexicana. 
Por um lado, o boom de commodities foi aproveitado pelo governo brasileiro, assim como por outros governos sul-americanos, para acelerar o crescimento e diminuir a desigualdade salarial; por outro lado, contudo, não é possível dizer que ele tenha contribuído para sofisticar a estrutura produtiva local. Ao contrário, a complexidade econômica brasileira parece ter diminuído no período recente ou, no limite, teria permanecido estagnada (a depender da medida utilizada). Embora a acumulação de reservas internacionais pareça proteger a economia de crises de balanço de pagamentos no curto prazo, as causas estruturais da vulnerabilidade externa ainda estão longe de serem superadas.

Não há dúvida de que muitos outros temas poderiam ser abordados em um balanço crítico da economia brasileira. Mas o dossiê contribui para interpretar as razões pelas quais a trajetória de crescimento econômico com redução de desigualdades salariais, observada entre 2003 e 2014 , foi súbita e bruscamente revertida. A acumulação de tensões relacionadas ao acirramento do conflito distributivo eà financeirização das políticas sociais, de um lado, e os limites à efetiva redução de desigualdade impostos pelo sistema tributário vigente e ao crescimento duradouro resultantes das fragilidades da estrutura produtiva, de outro, eram razões suficientes para suspeitar que aquela trajetória enfrentaria dificuldades. Um debate sofisticado sobre a experiência recente deve levar esses elementos em consideração, para que esteja à altura de suas promessas, seus limites e suas lições.

FERNANDO RUGISTKY é professor da Faculdade de Economia, Administração e Contabilidade da Universidade de São Paulo (FEA-USP). É doutor em economia pela New School for Social Research, mestre em direito econômico pela USP e bacharel em direito e em economia pela mesma instituição.

\section{REFERÊNCIAS}

Carneiro, Ricardo; Baltar, Paulo; Sarti, Fernando (Orgs.). Para além da política econômica. São Paulo: Ed. Unesp Digital, 2018.

Furtado, Celso.Obra autobiográfica. São Paulo: Companhia das Letras, 2014.

Kalecki, Michal. "Political Aspects of Full Employment". Political Quarterly, v. 14, n. 4, pp.322-331, 1943.

Lavinas, Lena. "21st Century Welfare". New Left Review, n. 84, pp. 5-40, 2013.

Oliveira, Francisco de. "A economia brasileira: crítica a razão dualista". Estudos Cebrap, n. 2, pp. 4-82, 1972.

Singer, André. Olulismo em crise: um quebra-cabeça do periodo Dilma (2011-2016). São Paulo: Companhia das Letras, 2018. 